\title{
ATTVIDADE «IN VITRO» DA AMPICIINA E HETACILINA SOBRE AMOSTRAS DE SALMONELLA TYPHI
}

\author{
Ernesto Hofer *, Maria Marfisa Aguiar Vicente ** e Estevão José Colnago
}

Os autores, utilizando a técnica da diluição seriada em meio líquido, determinaram as concentrações minimas inibitórias da ampicilina e da hetacilina em 150 amostras de Salmonella typhi, isoladas em sua totalidade a partir de hemoculturas, no Estado da Guanabara.

Obteve-se como média das concentrações bacteriostáticas, $0,545 \mathrm{mcg} / \mathrm{mi}$ para ampicilina e $0,720 \mathrm{mcg} / \mathrm{ml}$, no caso da hetacilina.

Em uma das etapas do processo de fermentação empregado para a obtenção da penicilina $G$, tem-se a presença de elevado teor de ácido 6-aminopenicilânico, ao qual podem ser ligados vários radicais ou grupos prostéticos. Por tal mecanismo, foi possivel a síntese de diversas substâncias, que receberam a denominação genérica de penicilinas semi-sintéticas e que revelaram uma efetiva ação bactericida sobre grande número de espécies bacterianas .

Alguns destes novos antibióticos sintetizados, em particular a ampicilina e a hetacilina, demonstraram nos ensaios laboratoriais um amplo espectro antibacteriano, inclusive agindo sobre determinados grupos de bactérias Gram negativas, representantes da família Enterobacteriaceae, que notoriamente discreta sensibilidade manifestam à penicilina.

Acresce à importância destes dois novos farmacos, em vista dos resultados das experimentações farmacológicas, que assina- laram como uma propriedade característica e comum, a excreção por periodos prolongados através dos ductos biliares, em concentrações muito acima daquelas registradas na corrente sanguínea (1).

Com as atenções focalizadas nesta propriedade, evidenciou-se, nas investigações microbiológicas, a franca atividade "in vitro" da ampicilina e da hetacilina sobre alguns dos sorotipos do gênero Salmonella, notabilizando-se principalmente esta ação na espécie Salmonella typhi. Assim, baseados nesta característica, em princípio estudada apenas na ampicilicina, foi dado ensejo ao surgimento de vários outros ensaios, que se detiveram em analisar a sua eficiência terapêutica na difícil incumbência de tentar a erradicação do bacilo tífico, de localização vesicular nos portadores $(2,3,6,8,14)$.

Considerando, portanto, a importância fundamental representada pelo estado de portador crônico na manutençāo do ciclo

\footnotetext{
* Laboratório de Bacteriologia do Departamento de Microbiologia e Imunologia do Instituto Oswaldo Cruz, Guanabara.

* Laboratório de Microbiologia do. Instituto Estadual de Saúde Pública, GB. Recebido para publicação em 11.12.1972.
} 
epidemiológico da febre tifóide em uma área endêmica ou epidêmica, e, acima de tudo, as dificuldades encontradas na eliminação deste microrganismo em tal situação, justifica-se plenamente esta avaliação na qual se visou determinar os níveis de sensibilidade "in vitro" de ampicilina e da hetacilina, em 150 amostras de Salmonella typhi, isoladas no Estado da Guanabara.

\section{MATERIAL E MÉTODOS}

Foram empregadas no presente trabalho 150 amostras de Salmonella typhi, isoladas a partir de hemoculturas de casos de febre tifóide registrados no Estado da Guanabara, no período de 1965 a 1970 .

Para a avaliação da sensibilidade das amostras, diante da ampicilina * e hetacilina ** recorreu-se ao método de diluição seriada, em meio líquido, tendo como limites extremos as concentrações de 0,03 a $10 \mathrm{mcg} / \mathrm{ml}$ dos antimicrobianos citados.

No que tange ao meio de cultura, assinala-se o emprego de caldo triptose (Tryptose-Difco) adotando-se as recomendaçōes preconizadas por Gove e Randall (9) no que se refere ao inóculo, representado por volumes de $0,5 \mathrm{ml}$ da diluição $10^{-3}$ de cada uma das culturas de $24 \mathrm{hs}$, em caldo da mesma composição e origem daquele empregado no teste. Os tubos, em duplicata para cada diluição, foram incubados a $37^{\circ} \mathrm{C}$ durante 18 a 24 horas, efetuando-se a leitura a seguir, tomando como referência para esta a presença ou ausência de turvação no meio. Foi considerada como limite da concentração inibitória mínima aquela diluição na qual não se observou nenhuma forma de crescimento.

Para caracterizar a ação bactericida destas duas substâncias, foram efetivados subcultivos de todas aquelas diluições que revelaram ausência visível de crescimento, no ato da leitura para a determinação das concentrações mínimas bacteriostáticas. O procedimento empregado para observar tal propriedade consistiu na semeadura de uma alça de $4 \mathrm{~mm}$ de diâmetro, do material, em $10 \mathrm{ml}$ de caldo triptosado e em placas contendo agar triptose, mantendo-se após sob incubação a $37^{\circ} \mathrm{C}$ durante 24 horas.

* Polycillin (Laborterâpica Bristol S.A.). * Versatrex (Laborterápica Bristol S.A.).
A menor concentração de antibiótico no qual não foi observada, tanto no tubo como no placa, a presença de crescimento foi considerada como sendo a concentração bactericida.

\section{RESULTADOS}

Os resultados obtidos, tendo como referência as determinações nos níveis mínimos inibitórios encontrados nas 150 amostras analisadas, diante da ampicilina e da hetacilina, foram reunidos na Tabela $\mathrm{I}$.

Tomando por base tais resultados, calcularam-se as médias das concentraçōes minimas bacteriostáticas, situando-se estes dados em $0,545 \mathrm{mcg} / \mathrm{ml}$ para a ampicilina e $0,720 \mathrm{mcg} / \mathrm{ml}$; no caso da hetacilina. Diga-se, a propósito, que a análise estatística perpretada, confrontando estas duas médias, através do teste $t$-Student, não revelou diferença significativa, ao nivel de probabilidade de 0,05 .

Analisando, ainda, os dados configurados na tabela $I$, observa-se nitidamente, a brusca ascenção do número de amostras inibidas pela ampicilina, entre a faixa de 0,07 a $0,156 \mathrm{mcg} / \mathrm{ml}$. representando uma progressão de $8 \%$ para $24 \%$ de estirpes inibidas. Nas concentrações subseqüentes $(0,132$ e $0,625 \mathrm{mcg} / \mathrm{ml})$ não se tem tão acentuado aumento do número de amostras inibidas.

O mesmo fato também foi observado com a hetacilina, tendo esta, no entanto, manifestado inibição sobre as amostras com menor intensidade entre as concentrações 0,07 a $0,156 \mathrm{mcg} / \mathrm{ml}$, representando uma rando à ampicilina ao nivel de $0,132 \mathrm{mcg}$ / $\mathrm{ml}$. Um aspecto que veio influenciar de modo extraordinário na diferença das doses médias encontradas, refere-se a que, entre as concentrações de 1,56 a $10 \mathrm{mcg} / \mathrm{ml}$, foi encontrado um menor número de amostras com resistência à ampicilina do que à hetacilina .

Quanto à atividade bactericida, tanto a ampicilina como a hetacilina revelaram-se capazes de determinar a morte das amostras de $S$. typhi testadas, já na primeira ou no máximo até a terceira diluição imediata àquela em que se observou o efeito bacteriostático, em aproximadamente $98 \%$ das amostras. 


\section{COMENTÁRIOS E CONCLUSŌES}

A ampicilina e a hetacilina são dois derivados semi-sintéticos do ácido 6-aminopenicilânico, que apresentam certas características comuns, como a ampla ação antimicrobiana "in vitro", englobando esta atividade inclusive as Salmonellas e especialmente Salmonella typhi.

Confrontando o comportamento das duas penicilinas semi-sintéticas em determinadas provas, verificar-se-á que os resultados foram considerados mais satisfatórios para a hetacilina, citando-se entre as mais convincentes, a sua maior estabilidade em presença de $\mathrm{pH}$ ácido, favorecendo, por conseguinte, a melhor e maior absorção quando introduzida por via digestiva, além de apresentar niveis séricos e urinários mais elevados e prolongados, decorrentes da menor suscetibilidade de ser metabolisada e destruída pelas células hepáticas, assim como pela menor depuração renal $(4,15,26)$.

Dentre as propriedades fisiológicas cumpre salientar a excreção através da vesícula biliar, que embora sendo caracteristica comum a outros antibióticos, teve na ampicilina uma maior projeção. Por sinal, este aspecto foi detidamente analisado por Harrison e Stewart (10), demonstrando que em animais, após 1 a 3 horas da administração de ampicilina, já eram detectadas na bile concentrações que superavam com larga margem aquelas registradas na corrente circulatória

Admitem estes investigadores que o fato determinante dos níveis elevados e principalmente prolongados da ampicilina no fluxo biliar deve-se a um ciclo contínuo de absorção e eliminação desta substância através da mucosa entérica e do parênquima hepático.

Posteriormente, Scioli e Giusti (23) investigaram e confirmaram, que, tanto no homem como em animais de experimentação (ratos), também a hetacilina era capaz de efetuar a sua eliminação, em níveis tão elevados quanto a ampicilina, através da vesícula biliar.

Baseados em tais achados, inúmeros ensaios clínicos detiveram-se, em princípio, em analisar o valor da ampicilina, na tentativa de erradicar o bacilo tífico dos cha- mados portadores crônicos, que normalmente eliminam este agente etiológico por meio da bile e que demonstra uma extraordinária resistência a todas as condutas terapêuticas até então aplicadas.

Sob este prisma, devemos levar em consideração as assertivas clínicas dadas a conhecer por Russel e colaboradores (22) e Simon e Miller (24) sedimentados também em ampla revisáo da literatura, chegando à conclusão de que o emprêgo da ampicilina em elevadas doses e por períodos prolongados, canstitui, até o momento, a terapêutica mais indicada na tentativa de erradicar S. typhi em portadores crônicos.

Todavia, contrastando frontalmente com essa orientação, salientam-se com base nos resultados das várias investigações efetuadas, a discreta ou mesmo nula eficiência terapêutica demonstrada pela ampicilina em casos de febre tifóide. Aliás, nesse sentido infere-se a possibilidade futura da introdução do emprego da hetacilina, principalmente considerando-se os efeitos promissores observados nos ensaios clínicos e laboratoriais de Scioli e Giusti, assim como, nos de Chawla e cols. (5), que inclusive podem sèr equiparados àqueles alcançados através do uso do cloranfenicol.

Entre nós, destaca-se neste campo o trabalho de Farhat e cols. (7), que administrando a hetacilina a oito crianças, acometidas de febre tifóide, verificaram resultados francamente animadores na pronta resolução da doença.

Quanto ao aspecto da sensibilidade das amostras de Salmonella typhi, em particular diante da ampicilina, em vista desta constituir o maior acervo dos dados encontrados na literatura, evidenciam-se quase que na totalidade dos resultados analisados sua magnífica ação bacteriostática e bactericida, em concentrações relativamente baixas. Assim, as primeiras informações a este respeito, foram coligidas do trabalho de Rolinson e Stevens (20), que muito embora tenham utilizado apenas 11 amostras de Salmonella typhi, anotaram como concentrações limites de inibição à faixa de 0,25 a $0,5 \mathrm{mcg} / \mathrm{ml}$.

Verificaram, ainda, estes autores a circunstância particularmente favorável ao antibiótico de apresentar em geral níveis bactericidas distanciados apenas de um ou 
TABELA I

CONCENTRAÇÕES MINIMAS INIBITÓRIAS DAS 150 AMOSTRAS DE S. TYPHI, EM PRESENÇA DA AMPICILINA E HETACILINA

\begin{tabular}{|c|c|c|c|c|c|c|c|c|c|c|c|c|c|c|c|c|c|c|c|}
\hline \multirow{3}{*}{ ANTIBIÓTICOS } & \multicolumn{19}{|c|}{ Concentrações inibitórias $(\mathrm{mcg} / \mathrm{ml})$} \\
\hline & \multicolumn{2}{|c|}{0,03} & \multicolumn{2}{|c|}{0,07} & \multicolumn{2}{|c|}{0,156} & \multicolumn{2}{|c|}{0,312} & \multicolumn{2}{|c|}{0,625} & \multicolumn{2}{|c|}{1,25} & \multicolumn{2}{|c|}{2,5} & \multicolumn{2}{|c|}{5} & \multicolumn{2}{|c|}{10} & \multirow[t]{2}{*}{ Média } \\
\hline & No & $\%$ & No & $\%$ & No & $\%$ & No & $\%$ & No & $\%$ & Nọ & $\%$ & No & $\%$ & $\mathrm{~N}^{\circ}$ & $\%$ & No & $\%$ & \\
\hline Ampicilina $\ldots .$. & 3 & 2,0 & 12 & 8,0 & 36 & 24,0 & 39 & 26,0 & 43 & 28,6 & 13 & 8,66 & 2 & 1,33 & 1 & 0,66 & $1-1$ & 0,66 & 0,545 \\
\hline Hetacilina .......... & 4 & 2,66 & 11 & 7,33 & 26 & 17,33 & 42 & 28,0 & 40 & 26,66 & 18 & 12,0 & 5 & 3,33 & 2 & 1,33 & 2 & 1,33 & 0,720 \\
\hline
\end{tabular}


de dois titulos da diluição, acima daquelas registradas para o efeito bacteriostático.

Outros pesquisadores, como Stewart e cols. (25), Ross e cols. (21), Naummann (19), Kaye e cols. (13) analisando a ação da ampicilina sobre um pequeno número de amostras de bacilos tíficos, observaram a bacteriostase entre 0,39 a $1 \mathrm{mcg} / \mathrm{ml}$.

Os resultados até então assinalados foram amplamente confirmados por Knothe (16), que em 197 das 203 amostras de $S$. typhi analisadas obteve, como concentraçōes bacteriostáticas extremas, os niveis de 0,19 a $3,12 \mathrm{mcg} / \mathrm{ml}$.

Mais expressivos, ainda, são os resultados encontrados por Kaluzewski (12), na Polônia, particularmente em decorrência do elevado número de amostras examinadas. Assim, em 970 culturas de $S$. typhi, ressaltando-se que 874 provieram de portadores permanentes, verificou este Autor que a média das concentraçōes inibitórias mínimas foì de $0,57 \mathrm{mcg} / \mathrm{ml}$, situando-se em $1,6 \mathrm{mcg} / \mathrm{ml}$ a média da concentração minima bactericida. Le Noc (17), em 50 amostras de bacilos tíficos isolados na África, observou que 49 foram sensiveis até a concentração de $2 \mathrm{mcg} / \mathrm{ml}$, revelando apenas uma amostra resistente à concentração de $5 \mathrm{mcg} / \mathrm{ml}$. Também Manten e cols. (18), colecionando durante o periodo de 1939 a 1960, 610 amostras de $s$. typhi, isoladas na Holanda, encontraram apenas uma estirpe resistente às concentrações situadas entre 2 a $5 \mathrm{mcg} / \mathrm{ml}$ de amplicina.

Estabelecendo desta forma um confronto entre os nossos resultados e aqueles até então descritos, verifica-se com pequena diferença uma evidente semelhança dos niveis bacteriostáticos expostos nos vários trabalhos, acentuando-se fundamentalmente esse fato quando se compara a nossa média das concentraçōes inibitórias mínimas da ampicilina com aquela assinalada por Kaluzewski (12).

Outro ponto a ser destacado, com raras exceçōes na literatura consultada, é o de que a maioria dos ensaios é unânime em evidenciar a intensa atividade "in vitro" da ampicilina sobre as amostras de Salmonella typhi, em concentrações muito abaixo daquelas do nível médio sanguíneo, representada normalmente por $5 \mathrm{mcg} / \mathrm{ml}$. Ressalta-se, além disso, a semelhança do presente achado aos referidos por Rolinson e Stevens (20), que destacaram a extraordinária ação bactericida da ampicilina, em concentrações muito próximas daquelas anotadas para as bacteriostáticas.

Quanto à hetacilina, afora a investigação de Chawla e cols. (5), realizada na índia, nenhuma outra referência detalhando a atividade "in vitro" desta penicilina semi-sintética sobre Salmonella typhi foi encontrada. Observaram estes autores nas 32 amostras examinadas, empregando a técnica da diluição seriada em meio liquido, que nas concentrações de $50 ; 25 ; 12,5$, e $6,25 \mathrm{mcg} / \mathrm{ml}$, corresponderam respectivamente a $10 ; 10 ; 7$ e 5 amostras inibidas.

É mais que evidente, estabelecendo o cotejo desses dados com os nossos, a nítida divergência localizada essencialmente no número de amostras inibidas, nas diferentes concentrações caracterizando-se de modo acentuado nos achados de Chawla e cols., a extraordinária resistência demonstrada.

Cumpre também assinalar a destacada ação bactericida demonstrada pela hetacilina sobre as amostras analisadas, revelando um comportamento análogo ao relatado para a ampicilina.

Por fim, vale salientar que muito embora a ampicilina e a hetacilina tenham apresentado resultados dos mais satisfatórios no que concerne ao aspecto bacteriológico e tendo inclusive, em algumas ocasiōes paralelas, confirmação do seu efeito através dos ensaios clínicos, ainda assim, sedimenta-se no cloranfenicol a conduta mais racional para o tratamento da febre tifóide, mesmo se tendo o conhecimento da ocorrência de um certo número de recaídas e do aparecimento de portadores, após o seu uso.

Considerando essas circunstâncias analisadas e basicamente situando-se no problema da tentativa de erradicação dos portadores de bacilos tíficos, na qual se tem algumas informaçōes como as de Havlic e cols. (11) demonstrando a pouca ou nula eficiência do cloranfenicol, será recomendável nesta condição o emprego da ampicilina, reconhecida no momento como um elemento de importância capital na tentátiva de resolução deste grave problema de Saúde Pública. 


\section{AGRADECIMENTOS}

Consignamos ao Prof. Dr. Sávio Antunes, do Instituto Castello Branco da Fundação Instituto Oswaldo Cruz, os nossos agradecimentos pela análise estatística efetuada, assim como, aos Srs. José Caetano Alves e Sebastião Januário da Silva Filho, pela valiosa cooperação prestada nas tarefas auxiliares.

SUMMARY

By using serial dilution technique in broth the authors have determined the minimum inhibitory concentration of the 150 strains of Salmonella typhi isolated in their totality from blood cultures in the presenoe of ampicillin and hetacilin.

An average of the bacteriostatic concentration $0,545 \mathrm{mcg} / \mathrm{ml}$ for the ampicillin and $0,720 \mathrm{mcg} / \mathrm{ml}$ for the hetacilin was obtained.

\section{REFERÊNCIAS BIBLIOGRAFICAS}

1. AYLIFFE, G. A. J. \& DAVIES, A. Ampicillin level in human bile. Brit. J. Pharmacol., 24: 189-193, 1965 .

2. ANDERSON, K. F. - Ampicillin for typhoid carriers. Brit. Med. J., 2: 571$572,1964$.

3. BULLOCK, W. E. - Ampicillin therapy of Salmonella carriers. Summary of laboratory and clinical investigations. Amer. J. M. Sci., 246: 42-47, 1963.

4. BUNN, P. A., MILICICH, S. \& LUNN, J. S. - Pharmacological properties of Hetacillin in the Human. Antimicrobial Agents and Chemotherapy, American Society for Microbiology, 947-950, 1965.

5. CHAWLA, V., C H A N D R A, R. K. BHUJWALA, R. A. \& CHAI, O. P. A comparative trial of hetacillin and chloranphenicol in typhoid fever. $J$. Pediat., 77: 471-473, 1970.

6. CHRISTIE, A. B. Ampicillin for typhoid carriers. Brit. Med., 2: 876878, 1964 .

7. FARHAT, C. K., FUCS, M., PEREIRA JR., W., SHEINBERG, M. A., GUEDES, J. S. \&. \& AYROSA GALVÃO, P. A. - Febre tifóide na infância. Pediat. Prát., 34: 27-38, 1968.

8. GOURLAY, R, J. \& HALL, R. - Ampicillin in the treatment of chronic faecal excretor of S. typhosa. J. Trop. Med. Hyg., 69: 117-119, 1966.
9. GROVE, D. C. \& RANDALL, W. A. - Assay methods of antibiotics. A laboratory manual. Medical Enciclopedia. Inc., N. York 238 p. 1955.

10. HARRISON, P. M. \& STEWART, G. T. - Excretion of antibiotics in bile. Brit. J. Pharmacol., 17: 240-423; 1961.

11. HAVLIC, J ., HEJZILAR, M., DUOSKY, K. \& PAROUBEK, M. - M. Der chloramphenicolspiegel in Blut und Galle operierter Bazillenausscheider. Bbl. Bakt. I. Abt. Orig., 186: 116-125, 1962 .

12. KALUZEWSKI, S. - Wrazliwose na Ampicyline i chloranfenikol Szoze pów S. typhi wyosobnionych od nosicieli (Susceptibility to Amplicillin and chloramphenicol of strains of Salmonella typhi isolated from carriers) . Medycina Désw. Mikrobiol., 21: 31-136, 1969 .

13. KAYE, D., MERSELIS, J. C. \& HOOK, E. W. - Susceptibility of Salmonella species to four antibiotics: Ampicillin, Penicillin G, Chloramphenicol and Tetracycline. New Eng. J. Med., 269: 1084-1086, 1963.

14. KAYE, D., MERSELIS, J . G., ROCHA, H., PRATA, A. \& HOOK, E. R. Clinical experience in the treatment of typhoid fever and chronic typhoid carriers. Paper presented at Conference on Comparative Assessment of the Broad Spectrum Penicillin and Other Antibiotics, New York Acad. Sci., 12-13, 1966, New York. 
15. KIRBY, W. M. M. \& KIND, A. C. Clinical Pharmacology of Amplicillin and Hetacillin. Ann. N. York Acad. Sci., 145: 291-294, 1967.

16. KNOTHE, H. - Citado en Legler, F. - Posição da Ampicilina na terapêutica antibiótica com ênfase particular aos achados labnratorizis. A Folha Médica, 57: 965-982, 1968.

17. LE NOC, P. - Sensibilité a L'ampicilline de 578 souches bacteriannes isolées en Afrique. Bull. Soc. Path. Ex., 62: 468-476, 1969.

18. MANTEN, A., GUINÉE, P. A. M. KAMPELMACHER, E, H. \& VOOGD, C. E. - An Eleven-Year Study of Drug Resistance in Salmonella in the Netherlands. Bull. Wld. Org., 45: 8593,1971 .

19. NAUMANN, P. - Ácido 6 D- (-) alfaamino-alfa-fenil acetamido penicilânico. Actividad antibacteriana $Y$ concentrationes del preparado in vivo. Arzneim. Forsch. 12: 984-992, 1962.

20. ROLINSON, G. N. \& STEVENS, S. Microbiological Studies on a New Broad-spectrum Penicillin, "Penbritin”. Brit. Med., J. 2: 191-196, 1961.
21. ROSS, S., LOVRIEN, E. W., ZAREMBA, E. A., BOURGEOIS, L. \& PUIG, J. R. - Alpha-Aminobenzyl Penicillin New Broard Spectrum Antibiotic. J. A. M, A. 82: 2338-242, 1962 .

22. RUSSEL, E. M.; SUTHERLAND, A. \& WALKER, W. - Ampicillin for persistent typhoid excreters including a clinical trial in convalescence. Brit. Med., J. 2: 555-557, 1966.

23. SCIOLI, C. \& GIUSTI, G. - Hetacillin in the treatment of typhoid Fever. Clin. Med., 74: 68-70, 1967.

24. SIMON, H. J. \& MILLER, R. C. Ampicillin in the treatment of chronic téphoid carriers. Report of fiften treated cases and a review of the literature. New EngI. J. Med., 274: 807-815, 1966.

25. STEWART, G. T., COLES, H. M. T., NIXON, H. H. \& HOLT, R. J."Penbritin" An Oral Penicillin with Broad-spectrum Activity. Brit. Med. J., 2: 200-206, 1961 .

26. TUANO, S. B., JOHNSON, L. D. BRODIE, J. L. \& KIRBY, W. M. M. - Comparative Blood Levels of Hetacillin Ampicillin and Penicillin G. New Eng. J. Med., 275: 635-638, 1966. 